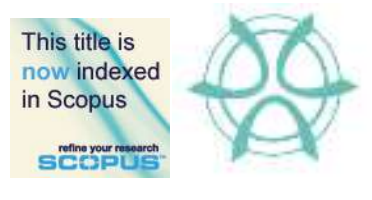

PLANNING MALAYSIA:

Journal of the Malaysian Institute of Planners

VOLUME 18 ISSUE 4 (2020), Page $33-46$

\title{
ARCHITECTURAL HERITAGE VALUES AND SENSE OF PLACE OF KAMPUNG MORTEN, MELAKA
}

\author{
Nur Raqena Mohd Rahil ${ }^{1}$, Mimi Zaleha Abdul Ghani², Yazid Sarkom ${ }^{3}$ \\ Center of Studies for Architecture, \\ Faculty of Architecture, Planning and Surveying, \\ UNIVERSITI TEKNOLOGI MARA (UITM), MALAYSIA
}

\begin{abstract}
Architectural heritage holds a variety of values towards the community and helps to enhance the image of a city. Currently, heritage sites all over the world are facing intense pressure from modernisation. This paper attempts to explore the relationship between the values of the architectural heritage of Kampung Morten, Melaka to its 'sense of place' amongst the community. To achieve this aim, the authors examine the occurrence of 'a sense of place', identify the architectural heritage values and analyse the challenges set by the surrounding modernisation. Methods of observation and interview were utilised in this study involving the heritage village of Kampung Morten in Melaka and its community. The findings from this study would highlight Kampung Morten's community level of attachment to their heritage village as they reflect their experience involving the 'sense of place'. In developing more sustainable urbanisation for Kampung Morten, this study also explores the community's level of awareness regarding the risk of modernisation.
\end{abstract}

Keywords: Architectural heritage, sense of place, urbanisation

2 Corresponding author: Senior Lecturer at UiTM. Email: mzaleha@uitm.edu.my 
Nur Raqena Mohd Rahil, Mimi Zaleha Abdul Ghani, Yazid Sarkom.

Architectural Heritage Values and Sense of Place of Kampung Morten, Melaka

\section{INTRODUCTION}

Architecture relates to the local identity of a place and culture. Unlike modern architecture, traditional architecture brings us back to our unique roots. The aesthetical value showcased through the detail of the traditional architecture is a physical proof of history reflecting the identity and character of a culture and community (Samadi, 2009). Psychologically, the sense of belonging helps a person to see values in life. As value is seen and felt by a person towards a certain place, attachment is created within the process and this builds up a 'sense of place'. On the other hand, acceptance as a member or a part is considered as the feeling of belonging (Hall, 2014). Inherited from generations, the distinctive architectural heritage has become a significant value as it is connected to the sense of belonging amongst the community. While urban development is inevitable, heritage conservation is seen as the most relevant way to sustain historic cities (Said, Aksah, \& Ismail, 2013). However, elements of historical architecture could suffer from deterioration caused by modernisation when a city goes through drastic changes in form and style, hugely departing from its local identity and subsequently losing its sense of place. This is among the reasons why protection of valuable heritage especially of heritage sites should be sustainable to ensure its longevity.

Today, the architectural heritage of Kampung Morten is heavily challenged by modernisation, affecting the sense of place nurtured by its unique heritage. The decaying of the conserved architectural heritage of Kampung Morten due to the modernisation weakens the area's sense of place as it interferes with the cultural identity, causing the loss of authenticity within the locality and shaken the state's title as UNESCO World Heritage Site. Previous research found that the values of heritage sites in Melaka are facing issues relating to authenticity and survival due to development and modernisation process of the city (Aziz, 2017).

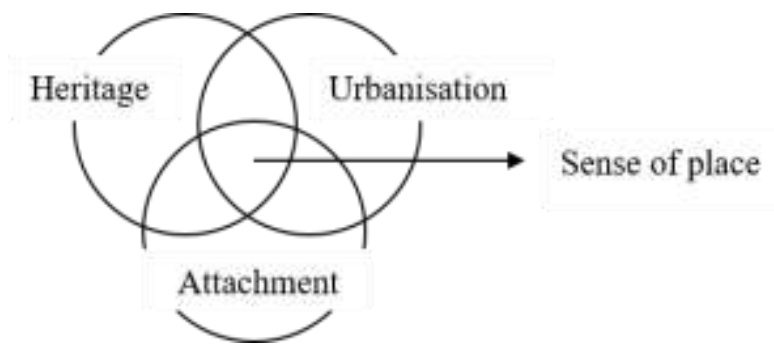

Figure 1: Relationship between heritage, urbanisation and attachment towards the "sense of place".

As illustrated in Figure 1, this study aimed to identify the heritage values of the architectural heritage of Kampung Morten, Melaka towards the 'sense of place' 
PLANNING MALAYSIA

Journal of the Malaysia Institute of Planners (2020)

through identifying the city through people-place attachment amongst the community. The study focused on the Malay traditional architectural elements of Kampung Morten. It involved exploring the sense of place amongst the local Malay community whom are the largest number of residents of Kampung Morten and directly experiencing the transitional impact of urban development towards modernisation. Findings from this study would establish the attachment between the community and the village, further suggesting the relevancy of the 'sense of place' within Kampung Morten. This could help to create awareness within the community on potential threats of modernisation and help increase the level of appreciation towards the value of conservation for architectural heritage sites like Kampung Morten, Melaka.

\section{RESEARCH BACKGROUND}

\section{Sense of place}

A place is a medium where traditions can be circulated and cultural reminiscence can be reproduced (Kathrin, 2012). The bond that connects those meaningful places to individuals is recognised as a place attachment (Altman \& Low, 1992). It is the experience of pursuing a connection to a specific place that holds specific meaning or value. On the other hand, the place attachment that each individual develop may be underpinned by different values (Quinn, Bousquet, \& Guerbois, 2019). Illustrated in Figure 2, the attachment built between a person and a place leads to a psychological aspect known as 'sense of place' (Jorgensen \& Stedman, 2001). Functional attachment is built through one's interaction with the particular place while emotional attachments are built through feelings that are felt towards the particular place such as the feelings of pride, love, and sadness (Tan, Tan, Kok, \& Choon, 2018).

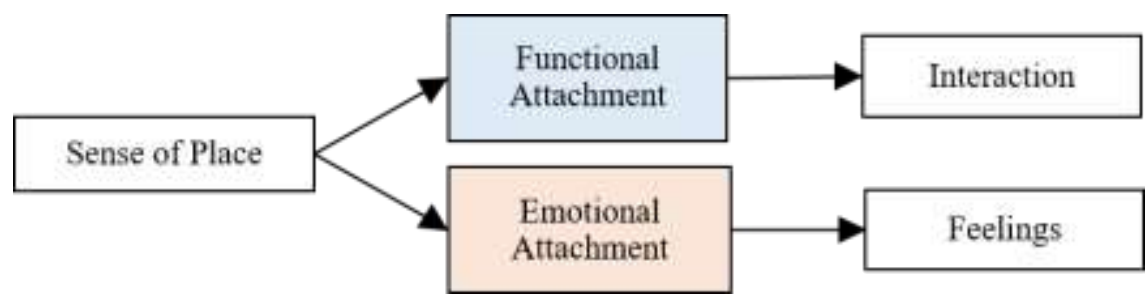

Figure 2: Types of attachment involves in the occurrence of 'sense of place'

A strong 'sense of place' is potentially built through the experience conveyed by the heritage buildings and live displays. The General Conference of UNESCO in 1972 states that heritage sites with significant importance should be protected to prevent the loss of cultural and natural heritage all over the world (Ertan \& Egercioglu, 2016). Failing in preserving and acknowledging heritage will lead to further loss of authenticity and identity along with the quality of 'sense of place'. 
Nur Raqena Mohd Rahil, Mimi Zaleha Abdul Ghani, Yazid Sarkom.

Architectural Heritage Values and Sense of Place of Kampung Morten, Melaka

Such concern is relevant to heritage sites in Melaka that are facing issues affecting the values as a result of the ongoing modernisation and development process of Melaka (Aziz, 2017). Othman (2017) added that urban development has caused the sense of place in some areas in Melaka to gradually fade as they experience physical changes that weaken their local identity and spirit. This is worrying because, without proper control of development, our local heritage will gradually be destroyed and replaced with a universal imprint (Samadi, 2009). Today, the modern development of Malaysian cities is accelerating fast (Said, Aksah, \& Ismail, 2013) resulting to such pressure on the building industry to respond to the contemporary modern and international style that has become a benchmark for the world's growth and advancement (Samadi, 2009). While modernisation is inevitable, conservation can be defined as a shield from any environmental or human force that threatens to impair the heritage (Aziz, 2017). This could reduce the development impact while balancing with local built heritage (Toore, 1999).

\section{Architectural Heritage Values}

Architectural heritage conveys the quality of richness and variations into the urban design and plays a significant role in enhancing the historical value and image of a city since it is acknowledged as a distinctive character that represents the history and the national identity of the community (Samadi, 2009). Heritage is also known as a strong element that is shared within a community where each member shares the value that is inherited from previous generations representing their uniqueness (Liu, 2017). Existence of heritage within a city helps strengthen the historical background of the city and acts as a medium in stimulating the city to potential visitors because the permanent heritage setting created through a well-restored heritage building turns a city into a more essential place to visit. The conserved values of a place and community are important as they are not only beneficial for the development of the present generation but also to be inherited and passed on to the future generations (Aziz, 2017). Table 1 shows the significant values and their indicators of Kampung Morten that include historical, aesthetical, social and economic.

Table 1: Types of values of Kampung Morten.

\begin{tabular}{|c|c|}
\hline Value Indicator & Significant Value \\
\hline Historical value & $\begin{array}{l}\text { - } \quad \text { Physical evidence of history } \\
\text { - Showcased legacy of the past }\end{array}$ \\
\hline Aesthetical value & $\begin{array}{l}\text { - Cultural design expressions } \\
\text { - Traditional features }\end{array}$ \\
\hline Social value & $\begin{array}{ll}\text { - } & \text { Strengthens the community } \\
\text { - } & \text { Retains traditions }\end{array}$ \\
\hline Economic value & - Commercial potential \\
\hline
\end{tabular}




\section{Attachment}

The attachments identified in Kampung Morten are divided into functional and emotional attachments (Tan, Tan, Kok, \& Choon, 2018). The table categorised the elements according to the pattern of words used by the respondents as shown in Table 2.

Table 2: Types of attachments of Kampung Morten.

\begin{tabular}{|l|l|l|l|}
\hline \multicolumn{2}{|c|}{ Functional Attachment } & \multicolumn{2}{c|}{ Emotional Attachment } \\
\hline \multicolumn{1}{|c|}{ Indicator } & \multicolumn{1}{|c|}{ Elements } & \multicolumn{1}{c|}{ Indicator } & \multicolumn{1}{c|}{ Elements } \\
\hline Engagement & $\begin{array}{l}\text { - Community's } \\
\text { social relation }\end{array}$ & Pride & $\begin{array}{l}\text { - History and legacy } \\
\text { - Uniqueness } \\
\text { - Tradition }\end{array}$ \\
\hline Reliance & $\begin{array}{l}\text { - Business } \\
\text { opportunity }\end{array}$ & Loyalty & $\begin{array}{l}\text { - No intention of } \\
\text { moving out }\end{array}$ \\
\hline Satisfaction & $\begin{array}{l}\text { - Facilities } \\
\text { - Services } \\
\text { - Accessibility }\end{array}$ & $\begin{array}{l}\text { Feeling } \\
\text { content }\end{array}$ & $\begin{array}{l}\text { - Lively atmosphere } \\
\text { - Acceptance }\end{array}$ \\
\hline Familiarity & $\begin{array}{l}\text { - Environment } \\
\text { - Lifestyle }\end{array}$ & Fondness & $\begin{array}{l}\text { - Environment } \\
\text { - Community }\end{array}$ \\
\hline
\end{tabular}

The main functional attachment between Kampung Morten and its residents is engagement through community's social relation and unity. Throughout generations, Kampung Morten's residents are a close-knit community that sharing engage the whole community in social activities including preparations for traditional ceremonies such as wedding and circumcision. The second functional attachment is reliance which occurs through the business opportunity in the village highly identified within the homestay owners and eatery operators as the needs for homestays have dramatically increased along with the advertisements of Kampung Morten as a popular tourist attraction in Malacca city. The third functional attachment is satisfaction and it is expressed through the availability and variations of public facilities, services and accessibility found in the village that may not be present in other villages as part of the government's commitments to promote Kampung Morten for tourism. The final functional attachment is a familiarity to the traditional way of living that has been practised from the earlier time. These traditions have shaped the unique environment of Kampung Morten that the village community feel attached to. 
Nur Raqena Mohd Rahil, Mimi Zaleha Abdul Ghani, Yazid Sarkom.

Architectural Heritage Values and Sense of Place of Kampung Morten, Melaka

On the other hand, the main emotional attachment between Kampung Morten and its residents is pride. Architectural heritage is one of the elements that hold value within the community and the city. Heritage prevails in Kampung Morten with its unique history, legacy, and traditions, turning Kampung Morten as a popular tourist village amongst Malaysians and outsiders. This has created a sense of pride amongst the community which is identified as an indicator for emotional attachment. Loyalty amongst the residents to remain in Kampung Morten with no intentions to move out from the village is another emotional attachment between the people and the place. Lastly is contentment which is the experience suggested through respondents' feelings of acceptance and the lively village atmosphere found in Kampung Morten. This emotional attachment is experienced even amongst the temporary residents as they feel highly accepted by the village community. Respondents also expressed their fondness through the growing bond between their community and the environment, reflecting the natural feeling of fondness that gives pleasure and happiness to people.

\section{Urbanisation}

Modernisation weakens the identity and character of Kampung Morten due to insensitivity of developments surrounding it, causing it to be sandwiched in between huge new structures, affecting its heritage essence (Aziz, 2017). It intrudes with the area's sense of place as it disturbs the design and culture and causes loss of local identity. The residents of Kampung Morten are aware of the ongoing physical transformation of the Malacca city surrounding their village. Highly commercial activities and developments of modern looking buildings and structures have affected the architectural language of Kampung Morten including the establishment of homestays and eateries within their village. Increase of pollution and new developments such as hotels and malls have also resulted in ground vibration causing damage to their timber buildings and structures.

\section{CASE STUDY \\ Kampung Morten}


Journal of the Malaysia Institute of Planners (2020)

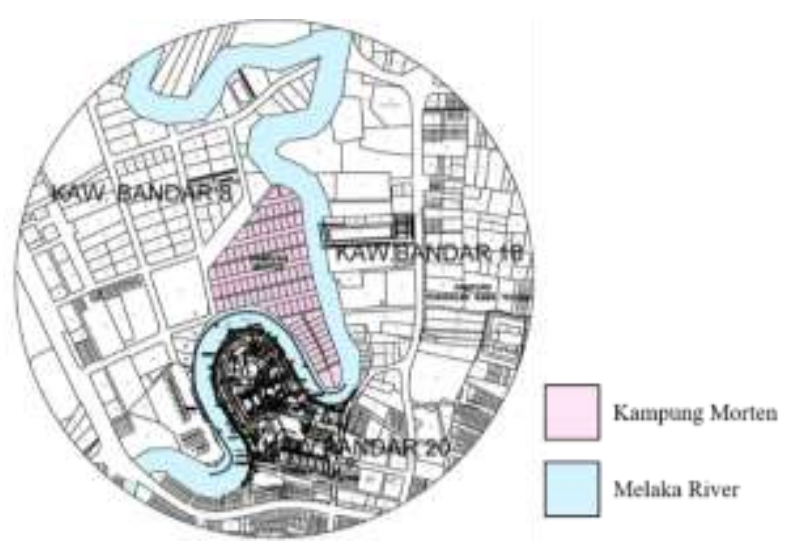

Figure 3: Municipality around Kampung Morten within a 500-meter radius.

(Source: Author)

A Malay traditional village, Kampung Morten is located in the heart of Melaka Town. Founded in 1923, it is amongst the oldest town in Malaysia; a heritage gem that portrays the uniqueness of the Malay culture not only through architecture but also lifestyle. This village of 5.02 hectares is circulated by Melaka River (Figure 3) and comprises of 98 building lots. Majority of the dwellings are single-storey structures built on stilts with lifted floor level, which is the common character of a traditional Malay house and structure. The present majority of residents of Kampung Morten range from the third to fifth generations, and are from the Malay race and practising Islamic religion.

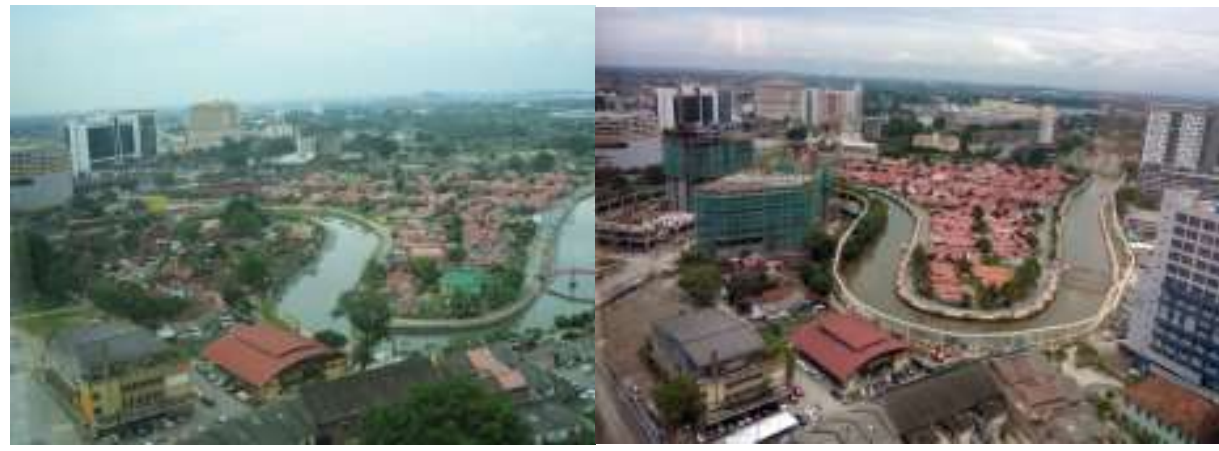

Figure 4: Perspective view of Kampung Morten from 2008 (left) to 2012 (right).

(Source: Ahmad, 2012)

Nestled between the modern fabrics of Melaka city, Kampung Morten is a 'living museum', preserving the Malay elements of traditions and practice. Figure 4 shows the rapid transformation of urban development surrounding 
Nur Raqena Mohd Rahil, Mimi Zaleha Abdul Ghani, Yazid Sarkom.

Architectural Heritage Values and Sense of Place of Kampung Morten, Melaka

Kampung Morten from year 2008 to 2012. The city of Melaka stated in its declaration to preserve the village, its heritage, and its sense of place. While museums are known as a building that stores and exhibit historical, cultural or artistic pieces, Kampung Morten serves as a living museum where parts of the village become the exhibit itself. The dwellings display various artefacts properly maintained by the community such as antique weapons, furnishings, appliances, and ceramics. In this living museum, the community of Kampung Morten carry out their cultural practices that have been inherited through generations.

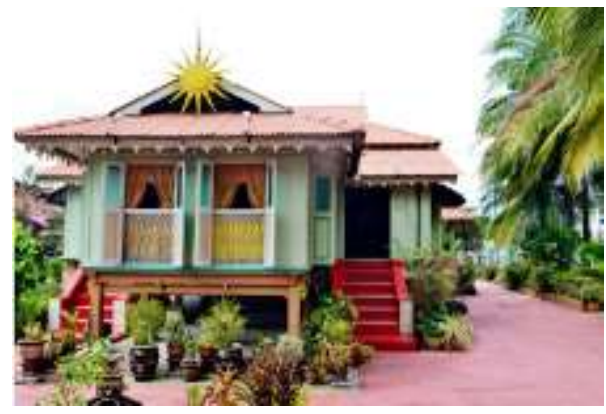

Figure 5: A residential heritage house in Kampung Morten (Source: Unknown, 2013)

The houses and structures that are established as a museum in this village have successfully retained the original and structural form for many decades and are occupied by living families. Besides maintaining both traditional exterior and interior of the building, the village museum is also complete with the traditional landscaping. The museum of Kampung Morten embodies a variety type of dwellings. They are characterised by specific activities or purposes assigned for each type of dwellings. Most of the residential houses in Kampung Morten still retain their traditional features, especially the roof design and the entrance or front part of the houses (Figure 5). However, some design changes are made at the tail-end of the houses. The original materials of the houses are also replaced by modern materials in some parts of the houses. Some of the houses in Kampong Morten serve as homestays to provide the experience of living in a real village to guests without having them to travel to the rural. Commonly, these homestays are either the existing and original residential houses or new structures attached to the living areas of the owners' original houses, or in some rare cases, built separately. This suggests that the commercialisation of Kampung Morten has affected and changed the original dwellings in application and design. 
PLANNING MALAYSIA

Journal of the Malaysia Institute of Planners (2020)

\section{Community Background}

Figure 6 illustrates the various status of residential of Kampung Morten. Amongst the 12 respondents, the permanent residents are the largest (41\%), followed by homestay owners (25\%), while museum owners and temporary residents share the same percentage of $17 \%$. Permanent residents and museum owners have lived in the village throughout their lives, suggesting that they inherited the dwellings from the previous generation.

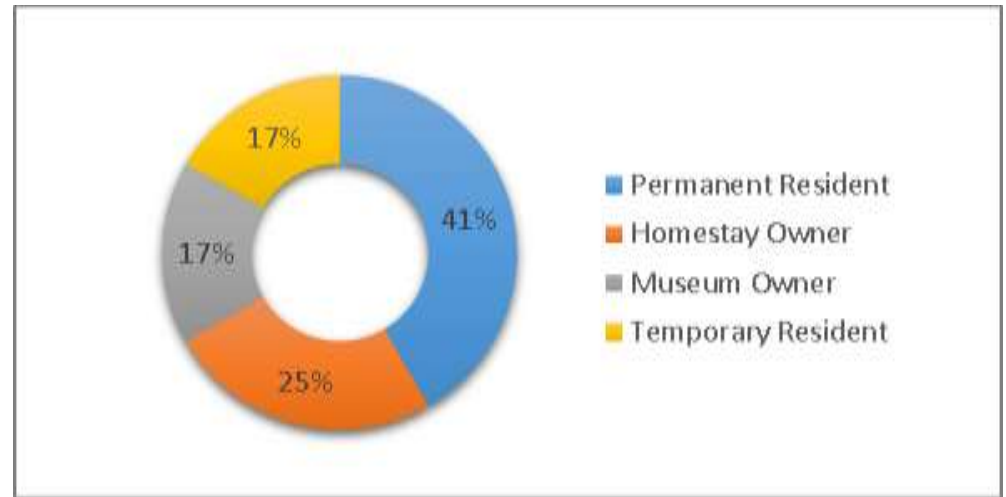

Figure 6: The various residential status identified in Kampung Morten.

\section{FINDINGS}

\section{Values of Architectural Heritage}

Majority of the respondents inherited their traditional houses from previous generations. This process of changing hands has disrupted the originality of the building form. As shown in Figure 7, only $20 \%$ of the respondents retain the original form of their houses compared to the other $80 \%$ who have carried out changes to their houses. The bar graph (Figure 7) further displays the types of residents that maintained or changed their building form. The study finds that the reasons for changes or renovations are mainly due to the occupants' current spatial needs. As for the permanent residents, one of the main reasons behind their house renovation is due to the expanding number of family members. Another important reason includes homestay owners having to accommodate and fulfil their homestay guests' needs. They also stated that maintaining or rebuilding the old traditional dwellings involve high cost, therefore, renovations are preferred. Despite the difficulties, the residents of Kampung Morten are still making all efforts to maintain the originality of their houses and structures, especially the entrance or the frontage. 
Nur Raqena Mohd Rahil, Mimi Zaleha Abdul Ghani, Yazid Sarkom.

Architectural Heritage Values and Sense of Place of Kampung Morten, Melaka
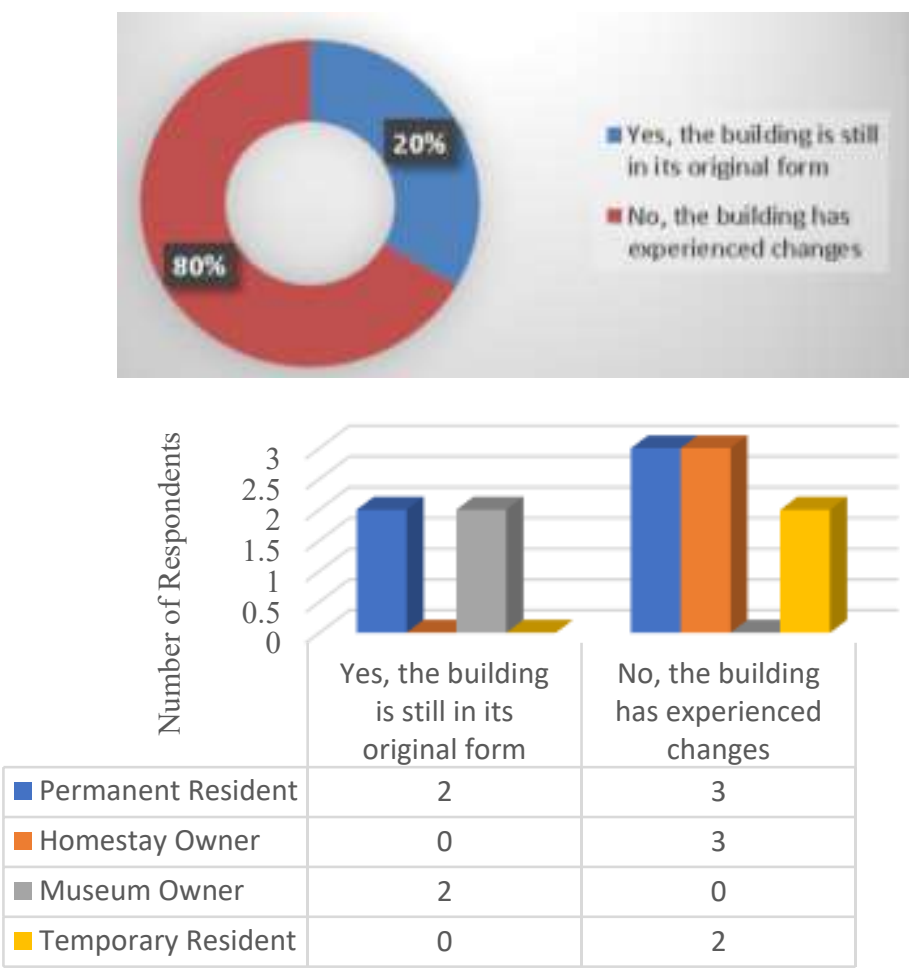

Figure 7: Types of residents and originality of building form

Every respondent agreed that conserved architectural heritage does carry significant value for future generations. Value indicators were established through the pattern found in the overall collected data that was analysed during data arrangement. This eased the process of data organisation and helped in providing a clearer data exposition. The insights from the respondents were then organised according to the indicators established. As shown in Table 1, the variations of value carried by the conserved architectural heritage in Kampung Morten are historical, aesthetical, social, and economical. The historical value serves as physical evidence of history as the dwellings that were passed down from one generation to the next is proof of a legacy lived throughout the past and present community. Besides traditional costumes, it is widely known that traditional architecture comprises unique cultural details and features. This aesthetical value is one of the values carried by Kampung Morten's conserved architectural heritage in terms of the traditional Malay architecture such as the interior arrangement, carvings, and wood decorations. As the conserved architectural heritage provides meanings to the community, it indirectly carries the social value in Kampung Morten. The bond within the community tends to grow stronger in their attempt to protect their heritage and traditions. Kampung 
Morten has been one of the commercialised elements of Melaka city for years now. As the world evolves, the idea of a traditional village in the middle of the city sure increases the merit of Kampung Morten, making it a worthy investment for the future. As stated by the respondent, this proves that the conserved architecture as part of Kampung Morten's heritage does carry an economic value that is beneficial for future generations.

\section{Sense of Place Through People-Place Attachment}

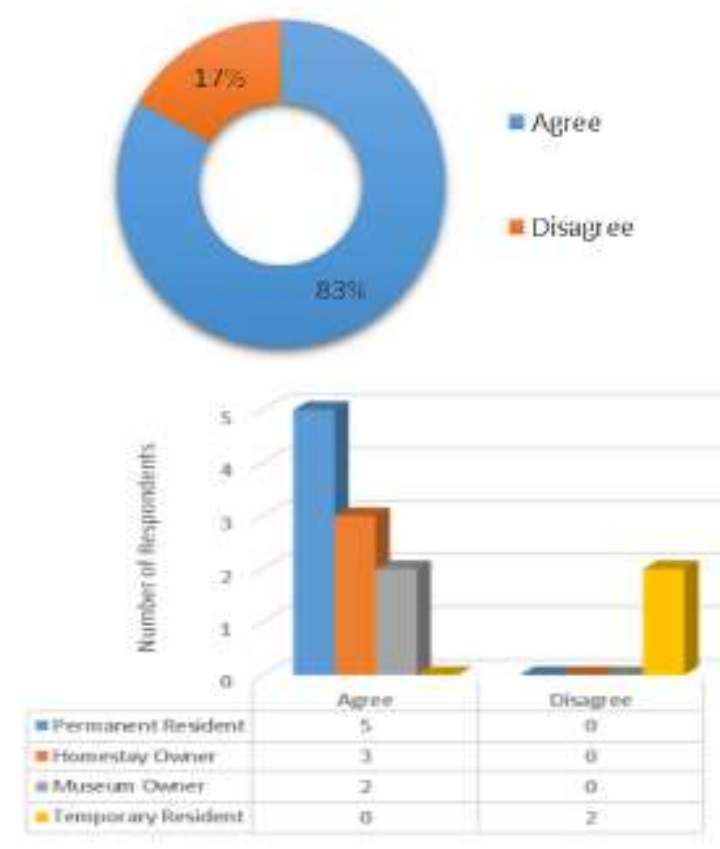

Figure 8: Respondents' agreement on the contribution of conserved architectural heritage to the 'sense of place' in Kampung Morten.

The 'sense of place' is identified through the experience of interactions between the respondents and Kampung Morten. According to Figure 8, 83\% of the respondents agreed that architectural heritage does contribute to the occurrence of 'sense of place' of Kampung Morten. However, $17 \%$ of the respondents who are temporary residents disagreed. The respondents stated that they felt more connected to the community of the village compared to the architectural heritage elements. They believed that the lifestyle and environment created by the community are the actual contributors towards the sense of place of Kampung Morten. On the other hand, they felt that the architectural heritage is merely the physical symbolisation of the culture behind the community. While 
Nur Raqena Mohd Rahil, Mimi Zaleha Abdul Ghani, Yazid Sarkom.

Architectural Heritage Values and Sense of Place of Kampung Morten, Melaka

their status was recorded as temporary residents of the village, this might have influenced their viewpoints compared to the permanent residents.

\section{City Modernisation and Urban Development}

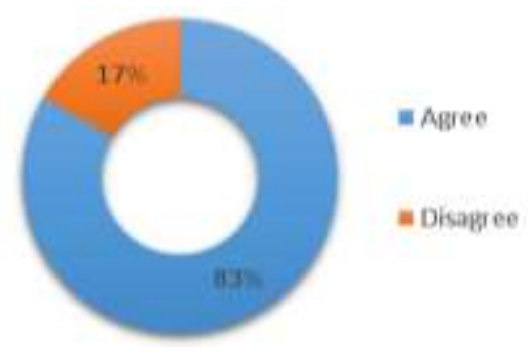

Figure 9: Respondents' agreement on the contribution of modernisation to the 'sense of place' in Kampung Morten.

Referring to Figure 9, $83 \%$ of the respondents also agreed that modernisation does affect the 'sense of place' of their area. The respondents had also stated that the modernisation surrounding their village had increased their insecurity on the probability of loss of attraction of their village. This suggested that modernisation has led to the decreased of the village 'sense of place' as the respondents are very much attached to their village through business reliance, services, and facilities. However, the minority (17\%) of the respondents disagreed with the statement as they believed that Kampung Morten is not affected by the surrounding development. They felt that the traditional village atmosphere of Kampung Morten is strong and would not be affected by the changes happening along its perimeter. This 'sense of place' of kampung Morten, they believed will remain for as long as the community continues to live there.

As the surrounding rapid urbanisation is leading Kampung Morten into high commercialised activities, the majority of the respondents have expressed their fear that the authenticity of their architectural heritage has been compromised for the sake of economic gains. This is mostly related to the establishment of homestays in the case study area. Another related aspect emphasised by the respondents relating to modernisation is involving the surrounding high-rise buildings that are soaring and overlooking onto their heritage village and the activities within it as shown in Figure 10. They felt that these buildings are affecting the presence of their village and slowly decreasing its attraction. They also expressed their concerns regarding the degradation effects on their environment due to urban development. 


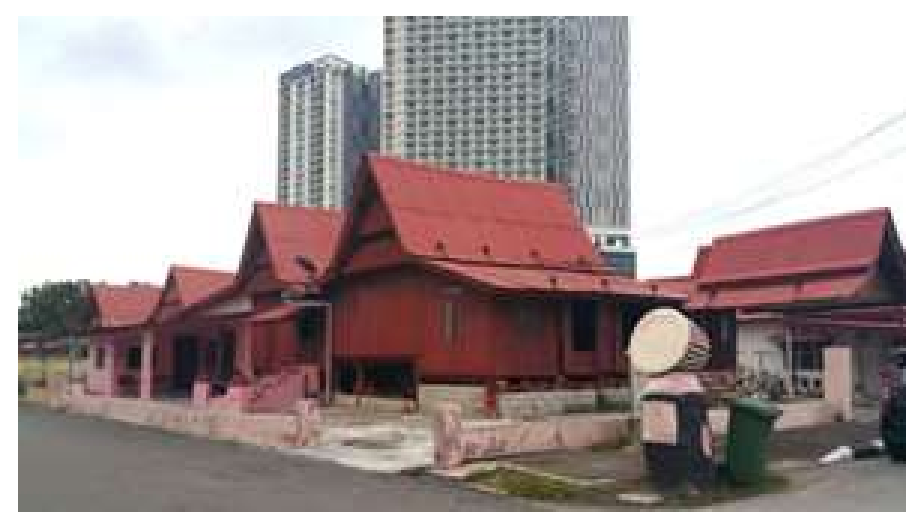

Figure 10: Residential houses in Kampung Morten with highrise backdrop.

Established as a 'living museum' by the government, Kampung Morten offers the essence of traditional Malay architecture through experience to its visitors which include eateries serving traditional food, living practices, decorations, landscape design and others. The government initiative is aimed to protect Kampung Morten from the rapid urbanisation surrounding it. As it generates economical gain to the residents, it has also increased the level of pride amongst the community as guardians of their heritage. While the majority of its residents agreed that it had generated positive impacts on their village and society in general, they also felt that this is creating extra burden as various expectations were placed by the government on their community. They were also worried if the architectural heritage of their village would reduce from the high tourism of their village that included the mushrooming of homestays and eateries.

\section{CONCLUSION}

Urban development and heritage conservation are important elements and need to be paralleled to achieve sustainable development. While conservation is beneficial for the present generation and future generations (Aziz, 2017), it is crucial to identify the values of Kampung Morten so that proper measures could be taken in the process to conserve them. This study had identified the values of architectural heritage and their relationship with the village's 'sense of place' as historical, aesthetical, social, and economical through qualitative interviews and quantitative surveys conducted amongst the residents of Kampung Morten. While some respondents had highlighted the crucial role of the community in shaping the environment and atmosphere of their village, this study has also indicated that the architectural heritage does contribute to the identified values and significant values of Kampung Morten. This is demonstrated through the people-place attachment, both functional and emotional, that occurs between Kampung Morten and its community. 
Nur Raqena Mohd Rahil, Mimi Zaleha Abdul Ghani, Yazid Sarkom.

Architectural Heritage Values and Sense of Place of Kampung Morten, Melaka

\section{ACKNOWLEDGEMENT}

The authors thank the community of Kampung Morten for their kind and valuable contributions to this research.

\section{REFERENCES}

Altman, I., \& Low, S. (1992). Human Behaviour and Environments: Advances in Theory and Research, Place Attachment. New York: Plenum Press.

Aziz, R. A. (2017). Heritage Conservation: Authenticity and Vulnerability of Living Heritage Sites in Melaka State. Kajian Malaysia, 39-58.

Ahmad Hidayat (2012). Projek tranformasi Kampung Morten dan Sungai Melaka telah berjaya. Blogsite: http://dayat2020.blogspot.com/2012/10/teranformasikampung-morten-dan-sungai.html

Ertan, T., \& Egercioglu, Y. (2016). The Impact of UNESCO World Heritage List on Historic Urban City Centers and Its Place in Urban Regeneration: The Case of Melaka, Malaysia and Tire, Turkey. Procedia-Social and Behavioural Sciences, 591-602.

Hall, K. (24 March, 2014). Create a Sense of Belonging. Retrieved from Psychology Today: https://www.psychologytoday.com/us/blog/pieces-mind/201403/createsense-belonging

Jorgensen, B. S., \& Stedman, R. C. (2001). Sense of place as an attitude: Lakeshore owner's attitude toward their properties. Journal of Environmental Psychology, 233-248.

Kathrin, D. (2012). Living Museum as a Way of Preserving Cultural Knowledge. Commodifying Culture? Cultural Villages and Living Museums (p. 39). Namibia: International Committee of Museums Ethnography International Council of Museums.

Liu, O. P. (2017). Community Involvement for Sustainable World Heritage Sites: The Melaka Case. Kajian Malaysia, 59-76.

Othman, R. N. (2017). The Impact of Gentrification on Local Urban Heritage Identity in Old Quarter, Melaka Heritage City. Planning Malaysia: Journal of the Malaysian Institute of Planners, 123-134.

Quinn, T., Bousquet, F., \& Guerbois, C. (2019). Changing Places: The role of sense of place in perceptions of social, environmental and overdevelopment risks. Global Environmental Change.

Said, S. Y., Aksah, H., \& Ismail, E. D. (2013). Heritage Conservation and Regeneration of Historic Areas in Malaysia. Procedia - Social and Behavioral Sciences, 418428.

Samadi, Z. (2009). Integrating Architectural Heritage an approach for Urban Revitalization. Selangor: University Publication Centre (UPENA).

Tan, S. K., Tan, S. H., Kok, Y. S., \& Choon, S. H. (2018). Sense of place and sustainability if intangible cultural heritage - The Case of George Town and Melaka. Tourism Management, 376-387.

Toore, M. (1999). Heritage Conservation and Values in Globalizing Societies. Retrieved from Getty Conservation Institute: http://www.chtalliance.com/about.htm

Unknown (2013). Kenali Villa Sentosa. Blogsite: $\mathrm{http}: / /$ rumahwarisanibrahimhashimvillasentosa.blogspot.com/

Received: $15^{\text {th }}$ May 2020. Accepted: $1^{\text {st }}$ Sept 2020 